ear, retain impressions made upon them for a monentary period after the cause has ceased to act. If this sumise is correct, then the following would ensue. All musical tones being produced by vibrations striking upon the ear in rapid succession, the first vibration would continue to be felt during the strotses of a number of succeeding vibration:.

The second vibration coming upon the ear befure the first ceased to be felt would produce the effect of two in the time of one, making the octave sound.

The third would produce the effect of three in the time of one, malking the octave fifth; the fourth, four in one, the double octave; the fifth, five in one, the double octave third, and so on,

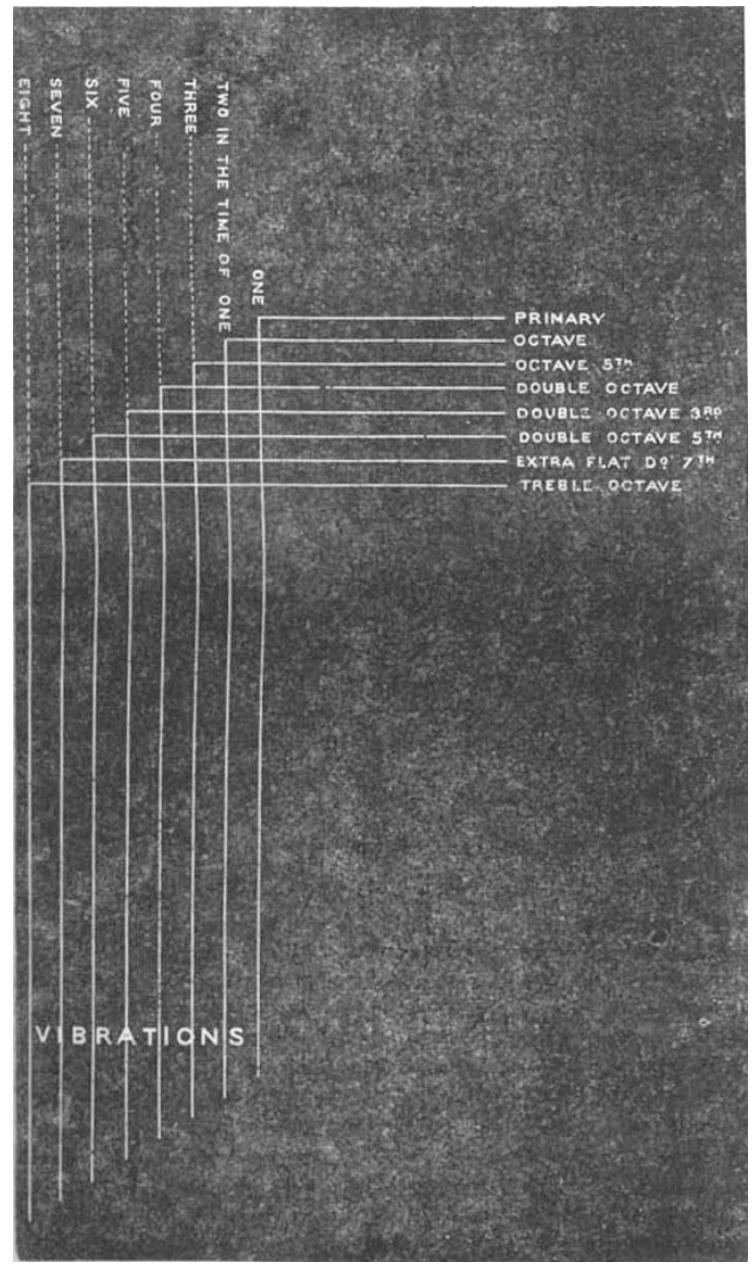

the order exactly corresponding with that in which the partials are heard.

Of course while the successive strokes occur the first is be coming fainter in effect, and thus each partial in the above order is heard with fainter intensity.

What the first vibration is to the second and its successors the second vibration is to the third and its successors, and thus the series of partials is kept up as long as the primary tone exists. 'This also accounts for the strong partials heard in the rough vibrations of the harmonium and the few partials heard from the smooth tones of the flute.

Chester, October is

IV. C. JONES

\section{The Green Sun}

ON Sunday, September 9, the residents in Colombo, while enjoying their evening stroll on Galle Face, were astonisbed by a strange appearance in the heavens. The sky was clondy, and frequent squalls were passing over the sea, one of which just touched Colombo. As soon as it was pait, the sun emerged from behind a cloud, of a bright green colout. It was then about $10^{\circ}$ above the visible horizon. The whole disk was dis. tinctly seen, and the light was so subdued that one could look steadily at it ; indeed I should say its intensity was scarcely halt that of the full mon. The same phenomenon was also observed on Monday and Tuesday. Wednesday was overcast, and I have not heard of any observations being made; and on Thursday the sun had resumed its normal appearance. I was not in a position to observe it in the morning; but from reports from other parts of the island I learn that the sun appeared green at its rising, and afterwards changed to blue, like the flame of sulphur, giving little light till it had attained an altitucle of about $20^{\circ}$, when it could no longer be watched with the naked eye. During the day the light had a bluish tinge; and in the evening the same phenomena were repeated in inverse order. The moon also, to some extent, was affected in the same way.

Can any of your correspondents give an explanation of this? It has been sugrested that a convulsion in the sun may have given prominence to vapours emitting a green light; but to me it seems more probable that the cause is to be sought in the upper strata of the earth's atmosphere. Can it have any connection with the recent volcanic eruption in the Straits of Sunda?

Colombo, September is

W.

In a clear sky, as the disk of the sun sinks down beneath the horizontal line of the ocean, the parting ray is a brilliant emerald green. I have occasionally, but not often, had the pleasure of seeing this interesting phenomenon, as the clear atmosphere has to be accompanied with a cloudless reoinn of the sky where the sun is setting. The same effect is not produced by the sun setting behind a distant bank of clouds. Probably the first ray from the rising sun would be the same unexpected colour.

Week St. Mary Rectory, Cornwall G. H. Horkins

\section{Pons' Comet}

This comet already has a tail, though a very faint one. With a $4 \frac{1}{4}$-inch refractor I traced it last night to a distance of $20^{\prime}$ from the nucleus, at a position angle of about $75^{\circ}$.

October 26

\section{Г. W. BACKHOUSE}

\section{Earthquake}

SEEING in your last issue (vol, xxviii. p. 623) that Mr. Cecil describes two distinct tremors of earthquale felt here by him, I write to say that the same phenomena were experienced by myself. I was disturbed in the night by what I mistook for an alarum going off, but found that it wa; a glass on my waterbottle vibrating violently. After a short pause the glass again vibrated. I found next morning that $I$ could exactly reproduce this sound by shaking the washing-stand. I have never known the washing stand to tremble before, even in a gale.

Pine View, Bournemouth, October 29

\section{H. HOWARD CRAWLEY}

STUDIES MADE ON THE SUMMIT OF THE
PIC DU MIDI WITH A VIEW TO THE
ESTABLISHMENT OF A PERMANENT ASTRONOMIC.AL STATION

THANKS to the indefatigable zeal of General de Nansouty and the engineer Vaussenat, a meteorological observatory has already been erected on the Pic du Midi. After visiting the place with the Director of the Higher Instruction on the occasion when this observatory was handed over to the State, Admiral Mouchez came to the conclusion that it might be possible to establish an unrivalled astronomical station on the summit, which is now perfectly habitable. In the month of August last he did us the honour of requesting us to study on the spot the advantages and possible drawbacks attending an installation made under such exceptional conditions. The details of our observations will form the subject of a special memoir far too extended for insertion in the Comptes Rendus. For the present our remarks must I Note by MM. Tholion and Trépied, from Comptes Rendus of Octoluer is. 